\title{
INTRODUCTION
}

\section{Confidence from experience: dual endothelin receptor antagonism in $\mathrm{PAH}$}

\author{
S.P. Gaine* and J. Behr\#
}

$\mathbf{P}$ ulmonary hypertension $(\mathrm{PH})$ is classified into five logical treatment-based groups [1]. Pulmonary arterial hypertension (PAH) represents the first of these five groups and is further classified as idiopathic (predisposing factors having been excluded), familial or as occurring in association with certain conditions, including connective tissue disease, congenital heart disease and HIV infection. PAH is characterised by increased pulmonary vascular resistance as a consequence of vascular remodelling, which ultimately leads to right heart failure and death. Few effective medical therapies were available for $\mathrm{PAH}$ $10 \mathrm{yrs}$ ago, and in many cases lung transplantation was the only viable treatment option. For patients with idiopathic PAH the outlook was bleak, with relentless deterioration and a predicted 5-yr survival of $22-38 \%$ [2]. Thanks to an explosion in research over the last $10 \mathrm{yrs}$, PAH has changed from an intractable, rapidly fatal condition to a serious but treatable disease.

Although the management of patients with $\mathrm{PAH}$ remains a therapeutic challenge, the situation is frustrated by the continuing delays in diagnosis. The early symptoms of PAH are nonspecific and, by the time other more common conditions have been investigated and ruled out, patients have often progressed to severe disease, their quality of life already seriously compromised [3]. Increased vigilance and the adoption of international guidelines will hopefully expedite this process and lead to earlier diagnosis.

Endothelin (ET) is believed to play a pivotal role in the early stages of $\mathrm{PAH}$ and targeting this peptide is an important therapeutic strategy. Indeed, elevated levels of ET have been detected in all forms of PAH [4-6], as well as in idiopathic pulmonary fibrosis (IPF) [7] and chronic thromboembolic pulmonary hypertension [8]. Despite distinct aetiologies, common histopathology suggests common pathogenesis and supports targeting ET as an appropriate strategy in all these conditions. Through comprehensive blockade of the ETA and ETB receptors, the dual ET receptor antagonist, bosentan, blocks the deleterious effects of ET. As a result of a number of clinical trials, it is widely acknowledged that bosentan not only improves exercise capacity in severely compromised patients but also results in cardiac remodelling, as measured by the Doppler right ventricular index [9], which is a prognostic factor for survival in PAH [10]. In addition, bosentan has been shown to delay time to clinical worsening [11] and to improve long-term outcome [12].

In the first paper in this issue of the European Respiratory Review (ERR), DupUIS [13] reviews the evidence supporting a pathogenic role for ET in PAH. DuPUIS [13] presents interesting pre-clinical data that highlight the potential benefits of blocking both the ETA and ETB receptor subtypes. The requirement for invasive right heart catheterisation for a definitive diagnosis of $\mathrm{PAH}$ requires effective collaboration and communication between respiratory physicians, rheumatologists and cardiologists. The paper by GIBBS [14] presents the cardiologist's point of view and highlights potential diagnostic pitfalls faced in pursuance of a timely diagnosis, recommending referral to specialist centres whenever possible.

Having gained an understanding of the biology behind the role of ET in PAH and the importance of accurate and timely diagnosis, the paper by HUMBERT [15] presents the mounting body of evidence in support of the efficacy of the dual ET receptor antagonist, bosentan. Several studies have shown that, in addition to providing symptomatic relief, bosentan can improve longterm outcomes in patients with $\mathrm{PAH}$, and research is now focused on combining targeted therapies to further improve the outlook for patients with $\mathrm{PAH}$. The management of $\mathrm{PAH}$ is not always straightforward and, before moving on to the potential for ET receptor antagonism in different indications, HOEPER and LAENGER [16] present details of challenging cases of $\mathrm{PH}$.

In the final article of this issue of the ERR, DU BoIs [17] introduces the ongoing studies of bosentan in interstitial lung diseases, including IPF, a severe progressive lung disease that is fatal in the majority of patients. As well as being a wellestablished pathogenic mediator in PAH, ET is

\section{AFFILIATIONS}

*National Pulmonary Hypertension Unit, Mater Misericordiae University Hospital, Dublin, Ireland. \#University of Munich, Klinikum Grosshadern, Munich, Germany.

\section{CORRESPONDENCE}

S.P. Gaine

National Pulmonary Hypertension

Unit

Mater Misericordiae University

Hospital

Eccles Street

Dublin

Ireland

\section{STATEMENT OF INTEREST}

S.P. Gaine has received: fees for organising education; funds for research; funds for a member of staff; and fees for consulting. S.P. Gaine has received fees for speaking from Actelion, Encysive, Schering and Pfizer, and has been reimbursed for travel to the ERS Congress by GlaxoSmithKline. J. Behr has received: fees for speaking and/or organising education from Actelion, ALK Scherax, Altana, AstraZeneca, Bayer, Boehringer Ingelheim, GlaxoSmithKline, Merck, Schering, Zambon, Encysive and ZLB Behring; fees for consulting from Actelion, Pari, Schering and Zambon; and research funds including funds for a member of staff from Actelion, Bayer Mondobiotech and Myogene. 
also thought to play a profibrotic role in the pathogenesis of IPF and IPF-related $\mathrm{PH}$, providing a clear rationale for the investigation of bosentan in IPF. The efficacy of bosentan in IPF continues to be investigated in the BUILD (Bosentan Use in Interstitial Lung Disease) clinical trial programme.

As the papers in this issue of the European Respiratory Review demonstrate, clinical trials have and will continue to play an important role in developing evidence-based treatment strategies for pulmonary arterial hypertension, as well as extending the application of endothelin receptor antagonists to other endothelin-mediated diseases. The outlook is brighter for patients with these chronic conditions.

\section{REFERENCES}

1 Galiè N, Torbicki A, Barst R, et al. Guidelines on diagnosis and treatment of pulmonary arterial hypertension. The Task Force on Diagnosis and Treatment of Pulmonary Arterial Hypertension of the European Society of Cardiology. Eur Heart J 2004; 25: 2243-2278.

2 D'Alonzo GE, Barst RJ, Ayres SM, et al. Survival in patients with primary pulmonary hypertension. Results from a national prospective registry. Ann Intern Med 1991; 115: 344-349.

3 Humbert M, Sitbon O, Chaouat A, et al. Pulmonary arterial hypertension in France: results from a national registry. Am J Respir Crit Care Med 2006; 173: 1023-1030.

4 Rubens C, Ewert R, Halank M, et al. Big endothelin-1 and endothelin-1 plasma levels are correlated with the severity of primary pulmonary hypertension. Chest 2001; 120: 1562-1569.

5 Vancheeswaran R, Magoulas T, Efrat G, et al. Circulating endothelin-1 levels in systemic sclerosis subsets - a marker of fibrosis or vascular dysfunction? J Rheumatol 1994; 21: 1838-1844.
6 Yoshibayashi M, Nishioka K, Nakao K, et al. Plasma endothelin concentrations in patients with pulmonary hypertension associated with congenital heart defects. Evidence for increased production of endothelin in pulmonary circulation. Circulation 1991; 84: 2280-2285.

7 Uguccioni M, Pulsatelli L, Grigolo B, et al. Endothelin-1 in idiopathic pulmonary fibrosis. J Clin Pathol 1995; 48: 330-334.

8 Bauer M, Wilkens H, Langer F, Schneider SO, Lausberg H, Schafers HJ. Selective upregulation of endothelin B receptor gene expression in severe pulmonary hypertension. Circulation 2002; 105: 1034-1036.

9 Galiè N, Hinderliter AL, Torbicki A, et al. Effects of the oral endothelin-receptor antagonist bosentan on echocardiographic and doppler measures in patients with pulmonary arterial hypertension. J Am Coll Cardiol 2003; 41: 1380-1386.

10 Tei C, Dujardin KS, Hodge DO, et al. Doppler echocardiographic index for assessment of global right ventricular function. J Am Soc Echocardiogr 1996; 9: 838-847.

11 Rubin LJ, Badesch DB, Barst RJ, et al. Bosentan therapy for pulmonary arterial hypertension. $N$ Engl J Med 2002; 346: 896-903.

12 McLaughlin VV, Sitbon O, Badesch DB, et al. Survival with first-line bosentan in patients with primary pulmonary hypertension. Eur Respir J 2005; 25: 244-249.

13 Dupuis J. Endothelin: setting the scene in PAH. Eur Respir Rev 2007; 16: 3-7.

14 Gibbs JSR. Making a diagnosis in PAH. Eur Respir Rev 2007; 16: 8-12.

15 Humbert M. Dual endothelin receptor antagonism: setting standards in PAH. Eur Respir Rev 2007; 16: 13-18.

16 Hoeper MM, Laenger F. Challenging cases in PH. Eur Respir Rev 2007; 16: 19-23.

$17 \mathrm{du}$ Bois RM. Blocking endothelin: breaking new ground. Eur Respir Rev 2007; 16: 24-29. 